\title{
O Naturalismo como Atitude: Mach em Disputa com a Metafísica
}

\author{
Antonio Augusto Passos Videira \\ Universidade do Estado do Rio de Janeiro/CNPq
}

\begin{abstract}
This article defends the hypothesis that Ernst Mach (1838-1916) employed naturalism (a word he never used) - an attitude which has its origin in Mach's acceptance of Darwinism - as a weapon against metaphysics, since the former would try to establish evalutions criteria, including those necessary to choose scientific theories, capable of being used by human beings.
\end{abstract}

Keywords: Mach, naturalism, metaphysics, history of science.

Quem conhece a evolução completa do desenvolvimento científico, julgará o significado de um [certo] movimento científico atual de uma maneira mais independente e exata do que aquele que, por ter o seu juízo limitado ao período de tempo em que vive, somente poderá basear-se na direção momentânea que tomou tal movimento.

E. Mach, História de la Mecánica, p. 18

Uma das mais importantes "verdades" da história da ciência moderna afirma que os cientistas, em especial os físicos, sempre alimentaram uma profunda desconfiança pela metafísica, quando não uma autêntica repulsa. Tomada em sentido estrito e como se desfrutasse de valor univeral, penso que essa tese é falsa. Ainda que seja impossível formular uma posição comum para os cientistas-filósofos atuantes entre fins dos oitocentos e início dos novecentos no que diz respeito à metafísica - se ela é efetivamente um obstáculo para o desenvolvimento da ciência, por exemplo creio ser inquestionável que um bom número deles não apenas aceitava a existência da metafísica, mas pensava que esta poderia dar algum tipo de contribuição positiva para a ciência. No entanto, creio que este é um trabalho que está por ser feito. Em outras palavras, penso que seria muito útil e instrutivo conhecer o "lugar" atribuído à metafísica pelos cientistas deste período. Apesar de não ser difícil mostrar opiniões positivas e favoráveis, a historiografia mais conhecida e divulgada ainda permanece aferrada à crença de que a metafísica sempre foi percebida como um problema ou um obstáculo. Por exemplo, entre aqueles que publicamente defendiam o completo afastamento entre ciência e metafísica, encontra-se a célebre figura de Ernst Mach

Principia 13(3): 371-84 (2009).

Published by NEL — Epistemology and Logic Research Group, Federal University of Santa Catarina (UFSC), Brazil. 
(1838-1916). Constitui um dos lugares comuns da história e da filosofia da ciência a tese de que Mach, desde a sua juventude, quando tomou aversão pela "coisa em si" kantiana, dedicou-se à elaboração de um pensamento científico-filosófico dentro do qual a metafísica não teria lugar. E mais: toda a sua "filosofia" deve ser compreendida a partir do seguinte "princípio": "É imperioso lutar pela exclusão da metafísica!"; este seria o seu principal leitmotiv. Em parte, tal leitmotiv foi disseminado pelos membros do Círculo de Viena a partir dos anos 1910 do século passado.

A repulsa que Mach nutria pela metafísica, todavia, não se explica apenas por sua rejeição do sistema kantiano, no que ele foi acompanhado por muitos cientistas seus contemporâneos. Além desta razão, deve-se mencionar uma outra, tão importante quanto aquela: sua preocupação em evitar que a separação entre ciência e senso comum se tornasse irreversível. O próprio principio de economia, talvez o mais célebre formulado por Mach, pode ser entendido como integrando a sua estratégia para evitar aquela separação. A importância que Mach concedia à teoria da evolução de Charles Darwin explica-se pelo mesmo motivo. Diferentemente do primeiro motivo, a rejeição a Kant, o segundo não é estritamente negativo; ele é construtivo, fixando-se a sua contribuição mais relevante na tese relativa à fundamentação, ou justificação, daquilo que se considera ser o conhecimento em parâmetros acessíveis à espécie humana.

O ponto de vista adotado no presente trabalho não procura, como é habitualmente o caso, discutir as críticas de Mach à versão newtoniana da mecânica ou ainda se a sua filosofia da ciência, marcadamente empirista e sensualista, impediria o progresso científico. Acredito que a maioria das análises históricas e filosóficas sobre Mach são formuladas a partir do desenvolvimento da física posterior à sua morte; desenvolvimento, que, a se crer nas opiniões correntes, desmentiu as suas principais teses, gerando a conclusão de que ele teria falhado no seu objetivo de formular uma concepção de ciência capaz de contribuir para o progresso desta última. Sua resistência ao atomismo é muitas vezes citada como prova de sua incapacidade de adaptar ao novo. Filósofos de inspiração marxista, os quais normalmente associam atomismo a materialismo, estiveram entre os principais críticos de Mach. Contudo, o que ocorre é que não se dá a devida atenção ao interesse de Mach pela promoção de mudanças, isto é, essas análises não levam em consideração o "motor" responsável pela possibilidade de obtenção de progresso: “... o fator que mais promove o pensamento científico é a ampliação gradual do campo de experiências." (Mach 1943: 222) A vontade e a necessidade de conhecer o novo, o incomum, ou ainda: aquilo que ainda não foi compreendido.

Não pretendo no escopo deste trabalho discutir se tais análises e conclusões são corretas. Uma análise historiográfico-filosófica do "destino" do pensamento de Mach ficará para uma ocasião futura. Ainda que não tenha espaço para justificar esta posição, parece-me que as análises sobre esse importante pensador austríaco de fins do 
século XIX e dos primeiros anos do século seguinte, não são completamente isentas, já que o compreendem a partir dos resultados da ciência. Mach parece-me sempre ser "acusado" de algum crime que supostamente teria cometido. Como no caso da sociedade brasileira, onde os acusados sempre têm que se defender, Mach, ou melhor, aqueles que acreditam em suas teses, devem, sob pena de receber um veredicto negativo, apresentar provas em favor das idéias do físico austríaco de origem checa.

É possível que o próprio Mach não se importasse com isso, uma vez que sempre se considerou um físico e não um filósofo. As atitudes dos filósofos lhes pareciam equivocadas; elas o seriam, posto que à filosofia, conforme Mach compreendia aquela que se fazia majoritariamente em seu tempo, caberia a determinação de um fundamento último e definitivo para o conhecimento. Em outras palavras, a filosofia parecia se ocupar principalmente com metafísica. Mach sempre se pautou pela busca de uma concepção de conhecimento que fosse livre de todo e qualquer traço de metafísica, já que não acreditava na capacidade da filosofia em dar respostas definitivas para questões referentes a temas, como, por exemplo, a origem do universo ou se existiria a alma. Ao escolher os cientistas como alvo principal para as suas publicações, Mach pretendia mostrar-lhes a inutilidade, quando não o perigo, das interrogações sem fim sobre a natureza última das coisas, como, por exemplo, da matéria ou do calor. O único meio para por fim a essas reflexões seria através do reconhecimento de que a matéria não é uma substância, mas, sim, um conceito, isto é, um símbolo de pensamento, que substitui um conjunto de relações que mantemos com os objetos e que estes mantêm entre si. A formação de tais conceitos é uma tendência natural nos seres humanos, tal tendência, todavia, pode se revelar desastrosa, donde perigosa, caso se considere que o termo designa uma substância verdadeira que existe de maneira incondicionada. É nesta crítica que se pode encontrar a crítica mais radical que Mach dirigia à metafísica. Uma verdade incondicionada estaria para além das potencialidades intelectuais dos seres humanos. Em outros termos, a metafísica deveria ser criticada, uma vez que ela dava origem a uma série de falsos problemas, irresolúveis porque mal formulados. Assim, pode-se pensar que Mach nutria como um de seus principais objetivos em mostrar o sem sentido de alguns dos problemas mais antigos sobre os quais a humanidade se debruçava tentando fornecer-lhes respostas.

Um ponto que deve ser enfatizado quando se analisa o pensamento de Mach é a sua preocupação em gerar uma imagem de conhecimento que esteja na medida do ser humano. Mach sempre lutou para que se reconhecesse que o conhecimento é humano, o que significa afirmar que ele foi gerado por homens para os seus semelhantes: "[O] conhecimento ... é um produto da natureza orgânica (Mach 1943: 217). De certo modo, pode-se considerar Mach um adepto da antiga fórmula de Protágoras: "O homem é a medida de todas as coisas." É aqui, na obediência a essa fórmula, que ele mais se aproxima do positivismo. Se o conhecimento deve ser ade- 
quado ao homem nada melhor do que recorrer às sensações, produtos da interação de todo e qualquer ser humano com o meio ambiente, uma vez que seria sobre elas que se poderia construir uma imagem de mundo comum aos homens, ao menos a uma maioria dentre eles.

Se filosofia fosse a produção de reflexões sobre a natureza última e definitiva do conhecimento, da verdade, do bem, entre outros temas, ela deveria ser recusada em favor de algo diferente, uma vez que a análise do conhecimento, bem como as produções intelectuais dos seres humanos, devem obrigatoriamente acontecer numa esfera acessível à fisiologia da nossa espécie. A suspeita de Mach com relação à filosofia era tão forte que ele repetidas vezes afirmou não ter criado nenhum conjunto de idéias e teses que merecesse receber tal denominação. Ao defender a crítica como instrumento privilegiado para a compreensão do conhecimento, Mach, mais do que se afastar da filosofia, pretendia reformulá-la. Tal reformulação deveria acontecer por meio da incorporação de uma das principais marcas distintivas da ciência, a saber: a sua enorme capacidade de comunicação. Ou seja: a filosofia deveria se dar por meio do diálogo. E o diálogo somente poderia ser uma realidade quando os filósofos reconhecessem que deveriam se reunir para trocar idéias.

O máximo que Mach dizia ter desenvolvido era uma metodologia de análise e uma psicologia do conhecimento. Tanto a primeira, como a segunda denominações para o pensamento de Mach, procuravam fixar as origens de certas idéias, o que seria feito no interior do desenvolvimento da história da espécie humana. Fora desta última, Mach pensava ser impossível compreender o surgimento e as transformações sofridas pelas teorias concebidas pelos homens. Os filósofos poderiam, segundo o próprio Mach, ver sua empreitada como sendo uma "clarificação filosófica da metodologia científica", a qual, entre outros resultados importantes, deveria fornecer os seguintes: (1) fixar que a coisa era uma abstração, enquanto que eram as sensações aquilo que existia realmente; e (2) Ao invés de causa, é necessário empregar o conceito de função; na natureza não existem causas ou efeitos, uma vez que ela se apresenta uma única vez. Com relação à causalidade, também o novo, ou o desconhecido, poderiam mostrar os seus limites: “... a crença nesse agente misterioso chamado causalidade, o qual mantém unidos pensamento e evento, é violentamente sacudido quando alguém entra pela primeira vez numa província da qual ele não possui nenhuma experiência prévia." (Mach 1943: 221, itálico no original.) Em suma, Mach é daqueles que, ao final dos oitocentos, defendeu a naturalização da filosofia, o que deveria promover a aproximação entre as ciências. Mas, não eram apenas as diversas ciências que se afastavam umas das outras, num movimento natural e desejável, posto que ele contribuísse para o progresso. A especialização não merecia ser condenada. Também a filosofia se afastava das ciências, evento que deveria ser combatido, pois ele geraria uma especialização excessiva fundada numa análise unilateral da prática e dos objetivos da ciência. Mach sempre desejou reapro- 
ximar ciência e filosofia, realizando isso através da determinação de que à segunda caberia compreender como as idéias da ciência surgiram e se desenvolveram.

A “clarificação filosófica da metodologia científica" está fundada na tese de que a comparação é um princípio básico para a formulação de conclusões a respeito do comportamento da natureza. Além de tornar possível o conhecimento, a comparação permitia a comunicação: "A comparação, como a condição fundamental da comunicação, é o elemento vital interno da ciência mais poderoso." (Mach 1943: 238). O lugar fundamental arrisco-me a dizer que Mach dava à comparação, levou-o a defender a necessidade de se empregar analogias e metáforas, outro ponto em que se distanciava de muitos dos seus colegas, com os quais mesmo comungando certos princípios gerais, afastava-se dos mesmos em função das excessivas inclinações "matematizantes" destes:

Essa relação entre sistemas de idéias, nos quais a dissimilaridade entre dois conceitos homólogos, bem como a concordância nas relações lógicas entre dois pares de conceitos homólogos, é claramente exposta, é denominada de analogia. [Ela] consiste num meio efetivo para o domínio, numa compreensão unitária [unificada], de diferentes áreas. A trajetória [para esse domínio] é simplesmente mostrada através da elaboração de uma fenomenologia física universal, a qual envolverá todas as áreas. (Mach 1943: 250, itálico no original)

Como sugerido acima, uma outra característica importante da atitude de Mach - penso ser melhor referir-se ao seu pensamento como sendo uma defesa de uma atitude muito mais do que de um conjunto de idéias - é a sua tentativa de unificar a ciência, o que somente seria possível se se recorresse à crítica, construída sobre uma genealogia histórica. Mach sempre se manteve fiel à idéia de que a análise histórico-crítica deveria ser considerada como completa com o reconhecimento de que sensações encontram-se na sua origem. Em outros termos, a análise não deveria ir além da determinação das sensações que estão na base das idéias com conteúdo cognitivo. São os pensamentos que devem se adaptar aos fatos, adaptar-se entre eles e não os fatos que devem se adaptar aos pensamentos. Esta tese restringiria em muito o campo de ação de afirmações sem base empírica. Ainda assim, não se deve concluir que Mach fosse contrário ao uso de hipóteses, sendo, ao contrário, recomendável, desde que se tomasse cuidado com o seu emprego:

A construção de hipóteses, portanto, não é um produto de métodos científicos artificiais. Este processo é, inconscientemente, transmitido desde a mais antiga infância da ciência. Mesmo mais tarde, as hipóteses só se tornam perigosas e danosas para o progresso quando mais confiança lhes é atribuída do que aos próprios fatos. (1943: 229)

Todas as idéias científicas encontram sua origem na interação do homem com o seu ambiente natural. A história da ciência funcionaria como um sustentáculo da teo- 
ria machiana do conhecimento. Ao mostrar de que modo as idéias cientificas apareceram e se transformaram, Mach desejava contribuir para a libertação dos bloqueios epistemológicos que obstaculizavam a prática da ciência. Tal preocupação relembranos de que Mach se dirigia principalmente aos seus colegas cientistas e menos aos filósofos. Ou seja, o seu público leitor, tal como ele mesmo o imaginava, deveria ser composto primeira e principalmente por cientistas; era sobre estes últimos que Mach procurava influenciar.

No escopo deste texto, procuro adotar uma postura "simpática" à atitude de Mach. Não que eu queira criticar a filosofia, como ele o fez, mesmo reconhecendo que algumas de suas opiniões fazem sentido. O meu objetivo consiste em apresentar e discutir aquilo que me parece ser o cerne da atitude filosófica de Mach com relação ao "desvelamento" dos motivos que o levaram a se opor à metafísica. Como não era incomum em sua época, a postura anti-metafísica de Mach ligava-se à sua rejeição à tese de que existira um ser onipotente, onipresente e oniconsciente. É bem conhecido que Mach era ateu. A dupla rejeição da metafísica e da religião o influenciou sobre como deveria ser a visão correta do que é o conhecimento. É interessante observar a relação que Mach estabelece entre a rejeição à existência de entidades as quais os seres humanos não podem ter acesso e liberdade daí resultante. Essa relação certamente não era inovadora, podendo ser considerada como herdeira direta do Iluminismo. Quanto a mim, o interesse contido nessa relação negativa encontrase na coerência com que Mach a defendeu, bem como na defesa que fez das suas consequências.

Nós devemos ao Iluminismo a nossa crença na liberdade de pensamento, o que já era defendido por muitos círculos intelectuais como um valor universal ao final do século XIX. Nessa época, disseminava-se a tese que de que seria necessário libertar a mente humana do ponto de vista que afirmava que a visão de mundo físicomecanicista teria primazia na tarefa de compreender o mundo. Esse "movimento de libertação" alcançaria a física, sendo uma consequência imposta à humanidade pelas novas tarefas do trabalho e da organização sócio-econômica. Se a física conseguisse deixar de conceder ao mecanicismo o primeiro lugar como fonte de inspiração para a explicação do mundo, ela realizaria aquilo que lhe cabe. Mach reconhece que a análise das tarefas e dos métodos da física não é exatamente uma ocupação do físico, mas, sim, do filósofo. Reconhecendo a existência de fronteiras disciplinares, ele pede desculpas por ultrapassar a fronteira da física com a filosofia, justificando-se com a afirmação de que o conhecimento é um problema que atinge e interessa a todas as áreas e que, por isso mesmo, fronteiras fixas e rígidas não podem ser traçadas: "Toda razão [motivo] que [nos] impele e estimula a modificar e a transformar nossos pensamentos procede daquilo que é novo, incomum e não compreendido." (Mach 1943: 222)

Além de nos levar a conhecer coisas até então desconhecidas, a natureza imporia

Principia 13(3): 371-84 (2009). 
à ciência uma atitude pluralista, como se pode perceber na citação abaixo:

Muitos lados, no entanto, possui a natureza. (...) Mas nós não precisamos imaginar que o progresso, por meio de trajetórias uma vez percorridas, é o único meio de atingirmos a verdade. (1943: 217, itálicos no original)

Descrevendo de modo direto, talvez excessivamente direto, o verdadeiro objetivo das teses científico-filosóficas de Mach, creio que o seu fim mais importante consistia no estabelecimento do conhecimento em bases puramente humanas. Se o conhecimento é produzido pelo homem e para o seu próprio uso, o mesmo deveria acontecer com a sua justificação. Neste ponto, atua, uma vez mais, a sua aceitação radical da teoria da evolução de Darwin.

A questão que mais o preocupava pode ser formulada do seguinte modo: se a mecânica não deve ser considerada como o fundamento da ciência, e nem mesmo o da física, como então determinar os critérios que serão usados para a escolha entre teorias científicas rivais, ou ainda: como reconhecer que uma teoria conseguiu realizar os seus objetivos de descrever os fenômenos naturais? Esta questão foi formulada por ele do seguinte modo:
Suponha-se, agora, que [se realizou] o ideal de alcançar uma dada provín- cia de fatos. Realiza a descrição tudo aquilo que o investigador pode per- guntar? Em minha opinião, sim. A descrição é a construção no pensamento de fatos e essa construção, nas ciências experimentais, é frequentemente a condição da execução real. Nossas imagens mentais quase são um substituto completo para os fatos e o meio pelo qual nós podemos assegurar todas as suas propriedades. (...) [A] ciência completa no pensamento fatos, os quais são dados apenas parcialmente. Isso é possível graças à descrição, já que a descrição pressupõe a interdependência dos elementos descritivos: de outro modo, nada poderia ser descrito. (Mach 1943: 252-3, itálicos no original)

Em suma, para Mach, era fundamental determinar o que poderia ser obtido por uma descrição.

O reconhecimento de que não seria possível evitar o uso de critérios para a avaliação do estágio alcançado pelo conhecimento não implica que a explicação para eles encontra-se na estrutura da razão. Uma vez que aquilo que os filósofos chamam de razão tem uma história, isto é, fruto de um processo evolutivo, não é mais factível pensar que ela é capaz de gerar uma crença insuspeita em seu funcionamento. A razão humana seria falível.

Mach não acreditava ser possível responder de modo definitivo à questão acerca dos critérios que deveriam justificar aqueles outros efetivamente empregues pelos físicos e demais cientistas naturais. De modo breve, estabelecer critérios (problema normalmente atribuído à epistemologia) é sinônimo de fazer metafísica, pois, para que os critérios pudessem realizar aquilo que se espera deles, sendo que uma das 
mais importantes de suas atribuições é a determinação do valor de verdade, seria preciso que eles estivessem ou fundados numa entidade transcendente, como Deus, ou fundados na natureza íntima das coisas. Reconhecendo, todavia, a impossibilidade de abdicar do uso de critérios, Mach procurou fixá-los de modo a que fossem o mais possível naturais aos seres humanos. Em outras palavras, Mach defendia que os critérios se originariam com a espécie humana; eles seriam fruto dos mesmos processos evolutivos pelos quais passou a espécie humana.

Para mostrar a naturalidade dos critérios, ou seja, determinar a sua origem no mesmo processo evolutivo que fixou (temporariamente) aquilo que somos atualmente, Mach recorreu à história. Ele é conhecido como um dos mais importantes historiadores da ciência do final do século XIX. Possivelmente apenas Duhem possa rivalizar com ele no quesito referente à relevância da história. No entanto, Mach, diferentemente do seu colega e companheiro de disputas filosóficas e científicas, nunca explicou com clareza o porquê de seu recurso à história. Mach cala-se sobre esse tema, talvez, assim, evitando construir uma teoria da história, o que lhe levaria a formular e a defender a necessidade de uma base apriorística para as suas descrições históricas. Se tivesse que construir uma teoria da história, as suas leis teriam que estar fora da história e, fora desta, nada poderia existir. Mach gostava de repetir a seguinte frase: "A história tudo fez, tudo pode ela transformar." (A citação não é literal.) A história parece não possuir leis, o que nos permite conjecturar que ela escapa à explicação, restringindo-se somente à descrição. Como justificativa implícita para o seu silêncio sobre a natureza da história, Mach, ao final do seu livro sobre o desenvolvimento histórico da mecânica, afirma que a sua concepção de economia do pensamento foi desenvolvida na sua experiência didática, através da sua prática de professor.

Ao acreditar que tudo foi feito pela história e que ela pode modificar tudo, Mach parece esposar uma noção restrita de previsão. Se a previsão tem limites, melhor seria não confundi-la com o conhecimento. Este deveria ser "maior" do que a previsão. Mach concedia um lugar especial à contingência como no caso da história, que seria o domínio da contingência e não da necessidade, tão cara aos filósofos. Ao ligar ciência e história, Mach procurava romper com o vínculo entre leis e teorias científicas e necessidade filosófica. Mas, postar-se ao lado daqueles que defendiam a contingência gerava um problema importante. Ainda que a história pudesse ser o domínio da contingência, ela não era arbitrária, o que poderia retirar-lhe toda inteligibilidade dos esquemas descritivos que dela decorriam.

A história também é importante, pois permite que nos familiarizemos com as descrições que construímos dos fenômenos analisados. Para Mach, explicar significa reconduzir fenômenos complexos a relações entre fatos e que são consideradas como mais simples. Uma das tarefas mais importantes da história da ciência seria mostrar, contra toda a aparência de arbitrariedade que se poderia imaginar em função da con- 
tingência que rege os eventos históricos, as motivações que presidiram à formulação desse conceito ou daquele enunciado.

Segundo Mach, a história da ciência era inseparável de uma epistemologia naturalizada, a qual ligaria a seleção de fatos, classificados como fundamentais, ao hábito e à história da nossa espécie. A análise histórica da ciência ensina-nos que é difícil estabelecer onde, quando e de que maneira começou realmente o desenvolvimento da ciência, parecendo natural admitir que o agrupamento instintivo das experiências fosse anterior à ordenação científica.

Mach, em suas análises sobre a ciência, defendia que os dados sensoriais, que ele denominava de elementos, formavam o bloco constituinte da experiência e da realidade. Assim, esperava impedir todo e qualquer discurso sobre entidades que existiriam para além da experiência humana. A ciência nunca deveria fazer uso de entidades que escapam à experiência humana, donde a sua aversão às teorias que empregavam átomos. Os conceitos fundamentais da física deveriam ser entendidas como cópias de experiências reais. O processo de construção de conceitos deve-se às nossas interações com o meio ambiente, estando em estreita conexão com as ações que realizamos cotidianamente:

Assim, pois, a ciência natural se propõe a investigar o que há de constante nos fenômenos, quais são os seus elementos e qual é a sua vinculação e dependência mútua entre eles. Ela [a ciência] se esforça em economizar, mediante uma descrição clara e completa, novos experimentos, [para] despreocuparmo-nos deles ... (Mach 1949: 17)

As observações anteriores não devem ser compreendidas como se para Mach a ciência nada mais seria do que mero refinamento do senso comum. A ciência era diferente do senso comum, na medida em que era abstrata e formalizada, sendo que essa segunda característica pressupunha o uso da matemática. No entanto, esse uso deveria ser parcimonioso para que se evitasse a elaboração de idéias sem referência a sensações, tomando como base apenas as idéias e equações matemáticas. A força da matemática era devida à sua capacidade em ser um instrumento útil na formulação concisa das observações, o que era fundamental para o esforço de poupar energia. Nas suas próprias palavras:

O conhecimento instintivo, involuntário, precede sempre ao seu conhecimento científico, consciente, vale dizer à investigação dos fenômenos. O primeiro nasce das relações entre os fenômenos naturais e a satisfação das nossas necessidades. A aquisição dos conhecimentos mais elementares não compete, sem dúvida [alguma], somente ao indivíduo, mas também ela é esperada para o desenvolvimento da espécie. (Mach 1949: 13, itálico no original)

Mach, como alguns de seus contemporâneos, reconhecia explicitamente que havia se instalado um fosso preocupante entre as diversas ciências. O final do século 
XIX já reconhecia publicamente que a prática cientifica se transformara em atividade de especialistas. Assim urgia, para Mach, bem como para outros de seus companheiros empiristas, construir uma base capaz de reunificar a ciência, o que não obrigava a elaboração de uma base comum para ela: o fenômeno da especialização, isto é, de subdivisão em disciplinas particulares, era um "resultado" normal do processo de transformação sofrido pela ciência moderna. A especialização ganharia um aspecto francamente negativo caso impedisse a comunicação entre as diferentes especialidades. Mas esse fosso não apenas atrapalhava o desenvolvimento da ciência, mas também o da própria humanidade, uma vez que esta ultima dependia, e cada vez mais, da ciência. Sem essa base unificadora, seria impossível à ciência realizar a sua obra maior, a saber: promover a melhoria da condição humana.

Como visto anteriormente, não constitui um exagero afirmar que Mach defendia que cientistas e filósofos reconhecessem que os problemas somente poderiam ser considerados como resolvidos, caso suas respostas fossem dadas em dimensões humanas, o que excluiria a possibilidade de serem definitivas. A dimensão humana das respostas apresenta-se, inclusive, na formulação dos seus problemas originais. Também os problemas devem ser formulados em termos humanos e não em termos absolutos como se o homem pudesse desfrutar da mesma posição dos deuses. $\mathrm{O}$ absoluto, ou em si, corresponderia a uma situação inatingível para todo e qualquer ser humano. Como o absoluto é inatingível, ele não serve como fundamento para o conhecimento. Ou ainda, a unificação do conhecimento não pode ser tentada em termos que não são compreensíveis aos seres humanos, ou seja, passíveis de serem vividos por eles. Neste ponto se apresenta uma característica fundamental do pensamento de Mach: todo e qualquer conhecimento nada mais é do que um instrumento de adaptação da espécie humana ao ambiente. Uma vez mais, percebe-se a influência do darwinismo no pensamento de Mach. É aqui que se encontra a origem do seu naturalismo.

Para Mach, a ciência não deveria alimentar o objetivo de explicar as engrenagens de uma hipotética realidade em si. Repetindo: o seu objetivo seria a economia de pensamento, isto é, a representação econômica daquilo que é factual. Para isso, dever-se-ia adaptar os pensamentos aos fatos, além de estabelecer uma adaptação entre os próprios pensamentos. As representações, por exemplo, os conceitos, não são definitivas, ou seja, não podem ser consideradas como prontas quando formuladas. Sua característica principal encontra-se na sua capacidade de ser continuamente aperfeiçoada. Sobre as representações, Mach afirmava o seguinte:

A representação mental que nos formamos dos fatos nunca são o fato total, mas, sim, aquele aspecto do mesmo que é, para nós, importante (...). Nossas representações são sempre abstrações. Também aqui podemos ver uma faceta do caráter econômico. (Mach 1949: 400)

Principia 13(3): 371-84 (2009). 
As representações são reproduções das interações entre os seres humanos e o seu ambiente. Elas tornam possível a reconstrução da experiência com o objetivo de economizar esforços aos homens. Seria a economia de pensamento, para Mach, o reconhecimento da finitude do intelecto humano? Penso que sim. Segundo o filósofo austríaco, a mente humana é limitada e, desse modo, é como que obrigada a proceder economicamente para que possa espelhar no seu interior a imensa riqueza existente no mundo externo. Sendo impossível ao ser humano apreender a realidade em toda a sua totalidade, só lhe restaria formular uma descrição do real que estivesse ao seu alcance, donde a exigência de que tal descrição fosse econômica. Em outras palavras, a economia aqui significa a possibilidade de o homem trazer consigo, ou seja, memorizar, a natureza "concretizada" nas representações, como as leis científicas.

A ciência seria, portanto, o conjunto de representações capazes de economizar os nossos esforços, uma vez que ela incorpora ao seu conjunto de leis aquelas representações que foram bem sucedidas, tornado possível que os homens se adaptassem ao seu ambiente:

Toda ciência tem que substituir, ou economizar, a experiência mediante imagens e representações mentais dos fatos; imagens que são mais fáceis de manejar que a própria experiência ... Com o reconhecimento do caráter econômico desaparece também toda a mística da ciência. (Mach 1949: 399)

Ou ainda: "Toda ciência tem por missão substituir a experiência." (Mach 1949: 406)

Mach sempre foi um defensor apaixonado do caráter econômico da ciência. Para ele, a ciência deveria principalmente nos ajudar na economia de esforços por meio da codificação dos processos adaptativos, os quais foram bem sucedidos anteriormente. De certo modo, a ciência é uma forma simples, fácil e coletiva de memorização daqueles resultados adaptativos que os seres humanos obtiveram ao longo da sua história. Em suas palavras, "[A] física é experiência arrumada de modo econômico (Mach 1943: 197)

A ciência para Mach é criada pelas e nas necessidades mais cotidianas dos seres humanos. Ou ainda: a origem da ciência encontra-se na prática e não na especulação. Em suma, a ciência origina-se na sociedade. Isso gera a seguinte implicação: não existe ruptura radical, ou abismo intransponível, entre ciência e senso comum. A prática científica mantém uma vinculação contínua com a prática cotidiana. A melhor maneira de compreendermos a natureza da ciência é através dos seus inícios "caseiros", ou seja, do papel que ela desempenhou, como ainda o faz, na luta do homem pela sua sobrevivência. É curioso observar que justamente na época em que se dissemina a tese de que o pensamento está vinculado à sobrevivência surgia, de modo avassalador, o sentimento de segurança, uma das marcas características do século XX. O conhecimento tem uma origem primitiva, o responsável pela solidez do 
pensamento científico: "Os maiores avanços da ciência têm sempre consistido [na obtenção] de uma formulação bem sucedida em termos claros, abstratos e comunicáveis daquilo que era há muito tempo conhecido [de modo] instintivo e, assim, tornando-o uma propriedade permanente da humanidade." (Mach 1943: 191) Ou ainda: “... as leis mais felizes [i.e. bem sucedidas] não caem do céu, mas emergem (saltam) de noções já existentes." (Mach 1943: 226)

A abstração e a formalização, marcas próprias da ciência moderna, em particular, daquelas que sofreram o impacto da matematização das suas fórmulas e representações como é o caso da física, não devem ser vistas como desconectando o mundo da vida daquele outro construído graças ao recurso do conhecimento científico. Para o nosso cientista-filósofo, a ciência é, acima de tudo, um instrumento de adaptação do ser humano ao seu ambiente. A ciência nunca poderá ser considerada pronta e completa; ela se encontra continuamente submetida a um processo de melhoramento. Jamais seria possível construir uma teoria científica definitivamente verdadeira do mundo. Todos os enunciados empíricos das ciências naturais têm um caráter hipotético. A ciência se move no domínio das conjecturas. As próprias teorias científicas nada mais são do que instrumentos provisórios.

\section{À Guisa de Conclusão}

Sou da opinião que Mach sempre defendeu uma concepção falibilista e revisionista de ciência. No entanto, isso não significa, ou melhor, não implica que a ciência seja instável. Ao contrário, uma de suas mais marcantes características é a sua estabilidade. Mas, o que gera tal estabilidade? Se não nos é possível conhecer a natureza última das coisas, não devemos procurar a base, ou o mecanismo, dessa estabilidade nas coisas ou na substância como uma filosofia essencialista procuraria realizar. Para Mach, a estabilidade deveria ser explicada por algum mecanismo que envolvesse diretamente os seres humanos. A ciência não é obra de deuses, mas, sim, de seres que são finitos, falíveis e contingentes. São os interesses humanos, e que se desenvolveram junto com a própria espécie humana, que vão, em última instância, explicar de que modo a ciência torna-se estável. O mecanismo humano que torna possível a estabilidade da ciência são os seus interesses, entre os quais se sobressai aquele ligado à sobrevivência da espécie. A estabilidade, tal como a existência da ciência, deve receber uma explicação naturalista: "A transformação das idéias aparece assim como uma parte da evolução geral da vida, como uma parte da sua adaptação a uma esfera de ação que constantemente se amplia.” (Mach 1943: 233)

Alguns cientistas-filósofos da estirpe de Mach, Poincaré, Bolztmann, Duhem, Einstein e Heisenberg entre outros, não apenas colocaram em discussão a existência da metafísica, mas, ainda que de modo conflituoso, defenderam, em certos casos, uma relação positiva entre esta e a própria ciência natural. Aqueles que defende- 
ram essa segunda posição, desconfiavam que a metafísica não se reduzisse a uma mera teoria sobre a constituição de objetos, principalmente daqueles invocados para explicar seja a composição, seja a estrutura dos fenômenos visíveis. Para além desses temas, a metafísica teria relação com o antigo e bem conhecido problema da orientação, a saber: qual o sentido da existência humana?

De que modo é possível perceber e mostrar a preocupação por parte de "nossos" cientistas-filósofos com a questão do sentido? Penso que uma possibilidade encontrase se direcionarmos o foco para as suas preocupações com o ensino, mais especificamente com os rumos que deveriam ser dados ao ensino de línguas clássicas e ciências naturais nos liceus e ginásios de seus países e épocas. Recorrendo a uma terminologia que se tornou famosa na segunda metade do século XX, os cientistas de finais dos oitocentos percebiam que o fosso crescente entre as duas culturas - científica e humanista - era preocupante.

Atendo-me especificamente ao caso de Mach, se, por um lado, é correto afirmar que ele favoreceu a posição que pregava a diminuição do número de horas de aulas de latim e grego, ele nunca o fez, defendendo as suas completas eliminações. $\mathrm{O}$ grego e o latim fazem parte da história de todo aquele que se considera um habitantes do espaço cultural e ideológico definido pelo Ocidente. Não ensinar as línguas clássicas e as idéias a elas associadas geraria uma situação inaceitável, uma vez que os resultados obtidos através do método histórico-crítico não poderiam nem mesmo ser reconhecidos, o que retiraria todo o seu valor. O que Mach desejava para o ensino era que este fosse capaz de treinar os jovens no exercício consciente e quotidiano da interrogação, da investigação e da formulação ousada de soluções para os problemas que atraíam a sua atenção. Em suma, o que me parece ser válido para aquilo que Mach entende ser ciência ou conhecimento, seja no que diz respeito ao seu ensino e à sua transmissão, seja no que diz respeito à sua criação, sintetiza-se na seguinte conclusão: o ser humano não pode esquecer-se de que o conhecimento e a sua transmissão existem para a promoção da sua liberdade e não o inverso. Finalmente, a liberdade humana somente poderia ser plena e autenticamente exercida caso procurasse conhecer e acolher o novo, consertando nas tradições recebidas aquilo que fosse necessário. Inversamente, o melhor critério para sabermos se um conhecimento merecesse ser visto como tal é se ele promoveria o sentimento de liberdade entre os seres humanos. Em suma, liberdade e conhecimento seriam complementares e indissociáveis.

\section{Referências}

Baç, M. 2000. Strucuture versus Process: Mach, Hertz, and the Normative Aspect of Science. Journal for General Philosophy of Science 31: 39-56.

Principia 13(3): 371-84 (2009). 
Blackmore, J. 1972. Ernst Mach — His Work, Life, and Influence. Berkeley, Los Angeles, Londres: University of California Press.

Boltzmann, L. 2004. Escritos Populares. (Seleção, Tradução e Introdução de Antonio Augusto Passos Videira) São Leopoldo: Editora da Unisinos.

Garreta, G. 2002. Ernst Mach: l'épistémologie comme historie naturelle de la science. In P. Wagner (org.) Les philosophes et la science. Paris: Gallimard (Folio/Essais): 624-58.

Mach, E. 1911. History and Root of the Principle of the Conservation of Energy. (Tradução de Philip. E. B. Jourdain) Chicago/Londres: The Open Court Publishing Co.

- 1943. Popular Scientific Lectures. (Tradução de Thomas J. McCormack) La Salle (Ill.): The Open Court Publishing Co.

- 1949. Desarrolo Historico-Critico de la Mecanica. (Tradução de José Babini) Buenos Aires/México: Espasa/Calpe Argentina.

Miguel, L. \& Videira, A. A. P. 2008. A Idéia de Evolução como Ponte entre Ciência, História e Evolução. Ciência \& Ambiente (Pensando a Evolução) 36: 71-85.

Wolters, G. 2001. Mach. In W. H. Newton-Smith (ed.) A Companion to the Philosophy of Science (Blackwell Companions to Philosophy). Londres: Blackwell Publishers: 252-6.

Antonio Augusto Passos Videira Departamento de Filosofia Universidade do Estado do Rio de Janeiro Rua São Francisco Xavier 524, sala 9027B

Maracanã 20550-013 Rio de Janeiro, RJ

Brasil

guto@cbpf.br

Resumo. Este artigo defende a hipótese de que Ernst Mach (1838-1916) recorreu ao naturalismo (termo que ele não usou) — atitude derivada da sua aceitação da teoria da evolução de Darwin - como arma contra a metafísica (aqui compreendida como uma atitude em favor da busca por fundamentação última, fixa e definitiva), já que procuraria estabelecer critérios de avaliação, incluindo os relativos à escolha de teorias científicas, efetivamente capazes de serem usados pelos seres humanos.

Palavras-chave: Mach, naturalismo, metafísica, história da ciência.

Principia 13(3): 371-84 (2009). 